\title{
Geodynamic controls on the storage of carbon and serpentinite in oceanic lithosphere
}

\author{
SUZANNE ATKINS ${ }^{1}$ AND ANDREW MERDITH ${ }^{2}$
}

${ }^{1}$ CNRS - École Normale Supérieure - PSL University

${ }^{2}$ Université Claude Bernard Lyon 1

Presenting Author: suzanne.e.atkins@gmail.com

Carbon and water are stored in ocean crust, mainly through alteration of basalt and peridotite at mid-ocean ridges. This sequestration of volatiles is a key link between the surface carbon system and that of the Earth's mantle. Tectonic processes transport the sequested carbon and other volatiles, which come from a mix of mantle and surface sources, from ridges to subduction zones, at which point they can enter the deep carbon system. In previous studies, Merdith et al. provided estimates of the mass of carbon and water delivered to trenches over the last $320 \mathrm{Ma}$, based on climatic, plate reconstruction and petrological modelling. We concluded that the subduction flux of carbon was mainly controlled by the global distribution of trenches. In contrast, the delivery of water to trenches was primarily controlled by the global spreading rate at ridges, due to the serpentinisation of tectonically exhumed mantle at slow and ultraslow spreading ridges. This study extends and compliments these results by testing the geodynamical plausibility of these conclusions. We use convection models to create self-organising ocean basins, the geometry of which are fully consistent with mantle convection. This allows us to test whether these conclusions are the result of assumptions made in the plate reconstructions or whether they are a fundamental feature of the global carbon cycle. It also gives us a method to extend our study beyond $320 \mathrm{Ma}$. Oceanic crust is rarely preserved in the geological record, and therefore ocean basin reconstruction, including the location of ridges and trenches, is impossible to verify further back in geological time. We use our geodynamical models to investigate the relationship between tectonic features that are preserved in the geological record and the geochemical processes of volatile sequestration and subduction. 